\title{
Compatibility and Safety Implications Associated with Interfacing Medical Devices in Neonatal Respiratory Care: A Case Example Using the Inhaled Nitric Oxide Delivery System
}

This article was published in the following Dove Press journal:

Medical Devices: Evidence and Research

\author{
Anthony L DeWitt' \\ Jaron Acker ${ }^{2}$ \\ Thomas A Larkin ${ }^{3}$ \\ Jim L Potenziano ${ }^{4}$ \\ Jeffrey M Schmidt $\mathbb{D}^{5}$ \\ 'Penumbra Seminars, LLC, Auburn, AL, \\ USA; ${ }^{2}$ Medical Device Marketing, \\ Mallinckrodt Pharmaceuticals, \\ Bedminster, NJ, USA; ${ }^{3}$ Device \\ Engineering R\&D, Mallinckrodt \\ Pharmaceuticals Ireland Ltd., Dublin, \\ Ireland; ${ }^{4}$ Scientific Affairs, Mallinckrodt \\ Pharmaceuticals, Bedminster, NJ, USA; \\ ${ }^{5}$ Device Development, Mallinckrodt \\ Pharmaceuticals, Madison, WI, USA
}

Correspondence: Anthony L DeWitt 2755 National Village Parkway, Opelika, AL, 3680I, USA

Tel +I $573230-4220$

Email aldewitt@aldewitt.com

\begin{abstract}
Over the past decade, international organizations have instituted strict regulations for the safe use of connected medical devices. The International Organization for Standardization and the Medical Device Single Audit Program instituted certifications to ensure that connected devices are compatible and operate within their proper clinical parameters. These efforts came about, in part, as a consequence of clinicians' decisions to use nonstandard, modified, or improvised devices for purposes outside the original manufacturers' approved parameters. Unapproved device modifications can be associated with increased risk of dosing errors, monitoring errors, tubing misconnections and serious or potentially fatal adverse events; furthermore, health care providers who implement unapproved device modifications may assume legal and financial liability should harm come to patients as a consequence of the modification. Using the inhaled nitric oxide delivery system as an example, the objective of this paper is to raise awareness of the potential dangers associated with unapproved modification and interfacing of therapeutic gas delivery systems and ventilators in the neonatal intensive care unit setting. The paper also highlights the rationale and necessity for rigorous validation processes that ensure that interfaced medical devices perform as intended in the clinical setting.
\end{abstract}

Keywords: patient safety, equipment failure, medical device legislation

\section{Introduction}

Safety and regulatory standards for medical devices have evolved during recent decades. ${ }^{1,2}$ The goal of these standards is 3-fold: (1) increased accountability; (2) assurance that the devices perform as the manufacturers intended; and (3) compliance with operational standards of international safety organizations such as the International Organization for Standardization (ISO), and regulatory requirements of the US Food and Drug Administration (FDA). ${ }^{1,2}$ Importantly, these standards encompass devices that have been modified for unapproved uses, applying even when a medical device is interfaced or connected with another device or system that has not been tested and validated for this use.

The international Medical Device Single Audit Program (MDSAP) allows for a single regulatory audit of medical device manufacturers' quality management systems that satisfies multiple regulatory authorities participating in the program (including those in Australia, Japan, Brazil, Canada, and the United States), and in 
some countries, MDSAP certification can serve as evidence for compliance with ISO standards. ${ }^{3,4}$ The ISO is an independent, nongovernmental, international body with a membership of 164 national standard organizations. The ISO has developed standards (ISO 13485:2016) for quality management systems designed to provide manufacturing specifications for products, services, and systems to ensure their safety, efficacy, and quality. These standards also apply to connected medical devices to ensure that these devices consistently meet regulatory and customer requirements. ${ }^{1}$ ISO 13485:2016 mandates that if the intended use of a medical device requires it to be connected or interfaced with other medical devices, a validation process must confirm that each device performs as it should and that all necessary requirements have been met when the devices are connected. This validation process must be completed before the device is released to the public. ${ }^{1}$

The ISO standard places the full legal responsibility on the manufacturer to ensure that medical devices comply with regulations. Any person who modifies a device (without acting on the behalf of the original manufacturer) assumes the role of the manufacturer and the liability that goes with it. ${ }^{1,5-7}$ Innovative solutions can sometimes be born of nonstandard use of routine medical equipment. However, if these solutions are not thoroughly and completely tested to the rigorous specifications of validation processes required by current regulatory authorities and safety standards, patients may be at serious risk of adverse consequences and health care providers may expose themselves to liability risks. In the United States, medical devices are classified by the FDA into 1 of 3 risk-based categories that determine the extent of regulatory control. ${ }^{8}$ Medical devices with low risk are assigned to the "class I" category, and those with moderate and high risk are assigned to "class II" and "class III", respectively.

There are numerous potential reasons why health care providers modify medical devices. Device modifications may be related to clinicians' need to fix technical problems that arise during treatment, to facilitate the efficiency of treatment, or due to limited resources or shortages of approved devices, among other reasons. In some cases, the use of on-hand items such as gauze, extra tubing, and/or tape for a "quick repair" of leaks in a respiratory apparatus may be perceived as a more efficient and/or easier solution than replacing the dysfunctional device or device component. ${ }^{9}$ For example, endotracheal tube leaks are common in intensive care unit settings; ${ }^{10}$ attachment of an intravenous (IV) catheter with a stopcock valve or packing the tube with gauze to mitigate the leak may be employed to restore pressure within the tube to avoid or delay reintubation. Sometimes medical devices are adapted for applications outside of their intended use to facilitate patient care. For example, polyethylene glycol oral solutions may be inserted into an IV bag and delivered into a patient's feeding tube via an IV pump to help promote bowel movements. As another example, Heimlich valves are one-way portable devices designed to prevent retrograde airflow in patients requiring respiratory support. ${ }^{11}$ These valves may sometimes be attached to urine collection bags or colostomy bags to facilitate fluid drainage in mobile patients. Assembly of "home-made" continuous positive airway pressure systems and other respiratory devices is often implemented in institutions with limited resources and in areas where there are shortages of approved devices. ${ }^{12,13}$ Finally, sometimes medical devices are created spontaneously without preparation or testing (in other words, they are improvised) to meet an unmet need in the absence of an approved device. For example, the modified circle ventilatory support system was developed to reduce oxygen requirements during long-distance transportation of ventilated patients. ${ }^{14}$

Using the inhaled nitric oxide (iNO) delivery system (an FDA class II medical device) in neonatal critical care as an example, this paper aims to raise awareness of dangers associated with unapproved modification and interfacing medical devices and to highlight the rationale for stringent validation processes that ensure interfaced medical devices perform as intended.

\section{Potential Risks Associated with Improvised Use of Connected Medical Devices}

Regulatory standards for the correct use of connected medical devices ensure that these devices are safely and effectively interfaced or connected in the clinical setting. ${ }^{1,2}$ Nonstandard, improvised connections have been described as fixes that are not rigorously tested in the laboratory or clinic over long periods of time to ensure that the modified medical devices function correctly and meet the original manufacturer's specifications and regulatory standards. ${ }^{15}$ Furthermore, as a consequence of introducing an unknown set of variables into the operation of 
the medical device system, improvised connections may hide a design flaw, or delay needed repair or replacement. ${ }^{9}$

Improvised connections between devices have been shown to lead to potentially catastrophic safety events for patients, as well as liability concerns for health care providers and institutions. ${ }^{15,16}$ The Joint Commission (formerly the Joint Commission on Accreditation of Healthcare Organizations) has reported tubing misconnections to be a major cause of severe patient injury and death, particularly in cases where universal luer connectors (designed to connect unrelated delivery systems) and improvised adapters (eg, using tubing or catheters) are used to make on-site modifications to medical device equipment. ${ }^{16,17}$

Ensuring proper tubing connections between devices is particularly important in neonatal settings. ${ }^{18,19}$ In 2006, The Joint Commission reported more than 300 cases of tubing misconnections: IV infusions connected to epidural lines (or vice versa); bladder irrigation solutions and enteral feeding solutions connected to peripheral or central IV catheters; IV infusions connected to indwelling bladder catheters and nasogastric tubes; IV solutions administered via tracheostomy cuff inflation tubes, pulmonary artery catheters, dialysis catheters, and others; and IV blood products transfused with primary IV tubing. ${ }^{18,19}$ Results of a literature review found 116 published case studies related to misconnections of feeding tubes intended for enteral lines to IV lines, many of which ultimately led to death $(n=21)$, sepsis $(n=16)$, renal impairment $(n=8)$, respiratory arrest/distress $(\mathrm{n}=2)$, and neurologic damage $(n=2) .{ }^{20}$ In these reports, the ease of interchangeable couplings was considered the key driver of the misconnections resulting in a "fundamental failure to protect patients."

The consequences of connection errors and improvised systems can also extend to respiratory devices. Until recently, the lack of an approved delivery system for the helium-oxygen mixture heliox required modification of devices that were not designed for the delivery of heliox. ${ }^{15}$ These modified systems increased the risk of anoxia and delivery of abnormally large tidal volume because of incompatible flow meters that were not designed to measure heliox. ${ }^{15}$ Delivery of inhaled epoprostenol through a non-standardized device has also been associated with a serious adverse event, resulting from a diluent reaction whereby the aerosol became sticky, causing the exhaust valve on the device to stick and malfunction and lead to substantial auto-positive endexpiratory pressure and hypotension. ${ }^{21,22}$ In fact, a recent report by the ECRI (formerly known as the Emergency Care Research Institute) alerted healthcare providers to potential harms to patients associated with off-label administration of epoprostenol via an IV infusion pump connected to a nebulizer for inhalation of epoprostenol. ${ }^{23}$ The report emphasized that this improper connection could lead to numerous sources of error and potential patient harms, including those associated with lack of device alarms or monitors to alert clinicians if therapy is interrupted, the potential for inadvertent connection of the infusion pump to the patient's IV line (which could cause overdose and catastrophic hypotension), potential ventilator malfunction due to the sticky properties of epoprostenol (potential for pneumothorax or other patient injuries), to name a few. Mislabeling of connections on interfaced devices can also result in device malfunctions. For example, in one reported case, mislabeling of the inspiratory limb of an anesthesia machine interfaced with an iNO delivery device caused the abrupt cessation of iNO therapy in a postsurgical cardiac patient; the expiratory and inspiratory limb labels on the anesthesia machine were transposed, and the iNO system was attached to the expiratory limb rather than the inspiratory limb. ${ }^{24}$ In this case, the source of the error was quickly identified and corrected before rebound pulmonary hypertension associated with the abrupt discontinuation of $\mathrm{iNO}^{25-27}$ could occur.

In some cases, an improvised system can jeopardize a patient's health because established safety protocols are not followed. For example, A. L. DeWitt observed a case where a binder clip and string ties were used to secure a patient's endotracheal tube, rather than tape (as was the requirement). High pressure from the clip caused the endotracheal tube to move into the patient's right mainstem bronchus compromising the patient's respiration, which required the endotracheal tube to be removed. In another case, a ventilated patient's respiratory therapist used a pocketknife to puncture a hole in the bottom of a water trap that had been installed to drain the ventilator tubing. This improvisation caused air and water to leak out of the punctured hole, and the patient developed hypoxia and hypercarbia.

For the fragile, critically ill patients in this setting, ventilator alarms play an important role in the safe administration of respiratory agents. However, intensive care units (ICUs) are often inundated with alarms, many of which may be false alarms, to the point that clinicians experience alarm fatigue. ${ }^{28} \mathrm{~A}$ recent prospective 
observational study evaluated the number of ventilator alarms occurring in three adult ICUs at a tertiary care university teaching hospital and showed that ventilator alarms were triggered 10,933 times over 1555 ventilatorhours during an 18-day study period, with an average of seven alarms per ventilator-hour. ${ }^{29}$ Each alarm triggered up to 8 notifications, and initial alarms that were not resolved within 15 seconds triggered additional alarms to alert more personnel. Another study investigated the frequency and cause of neonatal ventilator alarms recorded for 46 ventilated infants over a mean of 60 hours per infant. ${ }^{30}$ In this study, 27,751 alarms occurred over the course of 116 days, averaging 603 alarms per infant and about 10 alarms per patient per hour. In this study, alarms were most frequently caused by physiologic variability in respiratory rate or minute volume, inappropriate alarm limits, or maximum peak inflating pressure being too low during volume-targeted ventilation. Most alarms were very short in duration, but some were ignored for many minutes or hours. ${ }^{30}$ Results from another study of alarm frequency in the neonatal ICU of a university children's hospital found that 2176 alarms sounded over 7 days, but only $5.5 \%(n=119)$ were deemed clinically important. ${ }^{31}$

The impact of this overabundance of clinically insignificant or nuisance alarms can result in alarm fatigue or even ignoring or turning off alarms because trust in the alarm as a valid warning system has been lost. ${ }^{28,32}$ The percentage of these alarms that can be attributed to improvised systems is unclear. However, it can be surmised that any actions taken to circumvent the intended functioning of medical devices can increase the risk of adverse events, particularly in high-risk neonatal patients. Only devices and delivery systems that have been designed and validated to work together safely and effectively should be used. ${ }^{33}$ Furthermore, despite the good intentions and innovative potential of some improvised devices, the legal and financial liability for the modified device or delivery system rests with the person or institution that implemented the modification. ${ }^{15}$

\section{Case Example: iNO Delivery System \\ INOmax Delivery System Efficacy and Safety}

Inhaled nitric oxide (iNO; INOmax ${ }^{\circledR}$, Mallinckrodt Pharmaceuticals, Bedminster, NJ, USA) is a selective pulmonary vasodilator indicated to improve oxygenation and reduce the need for extracorporeal membrane oxygenation (ECMO) in term and near-term (>34 weeks' gestation) neonates with hypoxic respiratory failure associated with pulmonary hypertension. ${ }^{34}$ Several randomized, prospective, multicenter clinical studies in term and near-term neonates showed that iNO was safe and efficacious, significantly improving oxygenation and reducing the risk of death or the need for ECMO. ${ }^{35-37}$

\section{INOmax Delivery System Safety Measures}

The complexity of safely administering iNO involves the synchronization of several key components of the nitric oxide (NO) delivery system, including the delivery apparatus and the continuous integrated monitoring of $\mathrm{NO}$, nitrogen dioxide $\left(\mathrm{NO}_{2}\right)$, and oxygen $\left(\mathrm{O}_{2}\right)$, in addition to a ventilator. Failure of any of these connected components to operate as intended increases the risk of device error or failure and can lead to loss of or incorrect concentration of $\mathrm{iNO}$, inadequate or excessive ventilation or oxygenation, $\mathrm{NO}_{2}$ toxicity, and/or iNO and $\mathrm{NO}_{2}$ measurement error. ${ }^{2}$

Given the instability and critical condition of neonates with hypoxic respiratory failure and persistent pulmonary hypertension of the newborn, the iNO delivery systems (INOmax $\mathrm{DS}_{\mathrm{IR}}{ }^{\circledR}$ Delivery Systems, Mallinckrodt Pharmaceuticals, Bedminster, NJ, USA; Figure 1$)^{38}$ were intentionally engineered and tested with numerous built-in safety features and multiple backup systems. These features include a specially designed injector module that enables tracking of the ventilator inspiratory flow-time waveform and the delivery of a synchronized and proportional dose of iNO, continuous integrated monitoring of inspired gases $\left(\mathrm{O}_{2}, \mathrm{NO}_{2}\right.$, and $\left.\mathrm{NO}\right)$, a comprehensive alarm system that allows clinicians to adjust alarm thresholds and limits so they can differentiate between low-, medium-, and high-priority alarms (can mitigate alarm fatigue), a backup battery to maintain power for iNO delivery in the absence of an external power source, backup NO delivery capability, and dual-channel delivery to ensure constant, accurate gas delivery with the ability to shut down if monitored concentrations approach unsafe levels. ${ }^{38}$

Use of the INOmax delivery system with validated mechanical ventilators and other devices is required to ensure that both devices safely operate as designed. Inappropriate connection of an iNO delivery system to unvalidated devices (eg, nebulizers, anesthesia machines, 


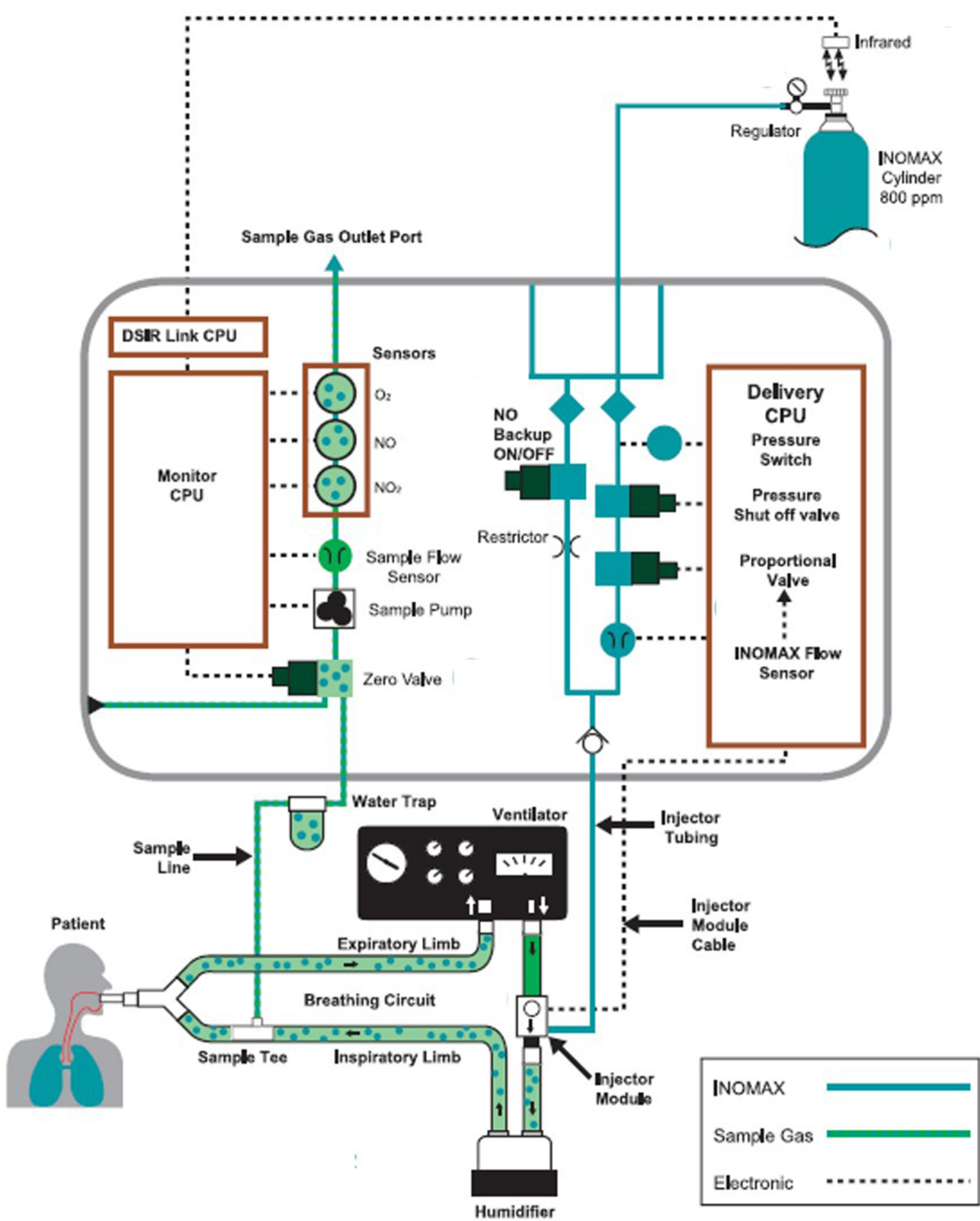

Figure I Schematic diagram of the iNO delivery system. The schematic of the iNO delivery device (INOmax DS ${ }_{\mid \mathbb{R}}{ }^{\circledR}$ Plus) is contained within the gray border. Nitric oxide from iNO cylinder (upper right of the diagram) enters the back of the iNO delivery device and passes through a filter and various safety valves within the iNO delivery device before entering an injector module located between the ventilator and the humidifier. Based on the ventilator flow and the set iNO dose, the injector module mixes the appropriate gas mixture flowing into the humidifier and the inspiratory limb of the ventilator circuit. The sample tee located in the inspiratory limb allows gas samples to be monitored by the iNO delivery device for NO, $\mathrm{NO}_{2}$, and $\mathrm{O}_{2}$ levels being inspired by the patient. Reproduced with permission from INOmax $\mathrm{DS}_{\mathrm{IR}}{ }^{\circledR}$ Plus Operation Manual, Mallinckrodt Manufacturing, Madison, WI, USA; $2014 .{ }^{38}$ Abbreviations: $\mathrm{CPU}$, central processing unit; $\mathrm{DS}_{\mathrm{IR}}$, inhaled nitric oxide delivery system; iNO, inhaled nitric oxide; NO, nitric oxide; ppm, parts per million. 
continuous positive airway pressure devices, life support systems) increases the risk of unreliable dosing, unreliable monitoring, alarm malfunction, or a complete system failure that can result in potentially serious health consequences. Safe discontinuation of iNO therapy requires a slow, gradual down-titration. ${ }^{39}$ Administration of iNO induces rapid, selective pulmonary vasodilation by increasing cyclic guanosine monophosphate concentrations in smooth muscle cells of the pulmonary vasculature. $^{25}$ The exposure to exogenous NO during iNO administration inhibits endogenous endothelial production of NO. ${ }^{25,27}$ Gradual down-titration of iNO therapy allows the patient's endothelial system to re-engage the production of endogenous NO. Several case studies of children and adults with hypoxic respiratory failure have shown that abrupt discontinuation of iNO therapy can lead to rapid deterioration in oxygenation, rebound pulmonary hypertension, hemodynamic instability ${ }^{26,40}$ and in some cases fatal cardiopulmonary failure. ${ }^{40}$ The risk for potentially life-threatening rebound pulmonary hypertension associated with abrupt and/or unplanned cessation of iNO is well documented ${ }^{25-27,40-42}$ and is a critical safety consideration that should not be underestimated. ${ }^{39}$ Rebound pulmonary hypertension syndrome can occur rapidly, after only a few hours of administration, and is independent of iNO therapy response. ${ }^{42}$ The risk of rebound pulmonary hypertension syndrome can be mitigated by vigilant monitoring and adherence to strict protocols for weaning patients from iNO therapy.

Another important safety consideration during the use of iNO is the avoidance of toxicity associated with the conversion of $\mathrm{NO}$ to $\mathrm{NO}_{2}$, which occurs when $\mathrm{NO}$ reacts with $\mathrm{O}_{2}$, particularly in high $\mathrm{O}_{2}$ concentrations within the ventilator circuit and airways. This could lead to pulmonary injury; ${ }^{43}$ methemoglobin levels also need to be carefully monitored during treatment with iNO to avoid tissue hypoxemia. ${ }^{35,36,44}$ One further safety consideration is that the iNO delivery system does not adversely impact ventilator performance.

In the clinical trial setting, safety risks were mitigated largely owing to the use of delivery systems that provided constant delivery of iNO and careful monitoring for toxicity. ${ }^{35,36,43,44}$ However, in everyday clinical practice, any unintended discontinuation or disruption on iNO therapy could increase the risk for a severe cardiopulmonary event or death. ${ }^{40}$ In improvised systems, the devices may be modified to function under a specific set of clinical circumstances but can fail when patient status changes and/or when clinical adjustments are needed, particularly in critically ill neonates. Also, given the precarious condition of these patients, timely and complete testing allowing for safe and effective adjustments may not be feasible and may place the patient's safety at risk. For these reasons, therapeutic delivery systems must be validated to ensure safe and effective functioning across all approved clinical scenarios and patient populations.

\section{The Validation Process}

Given that the safety and effectiveness of iNO therapy depends on the compatibility of the ventilatory support device and the INOmax delivery systems, the manufacturer has established a validation process, which meets FDA requirements, to ensure that the INOmax delivery systems operate within established parameters and specifications when connected to other devices. ${ }^{45}$ Relevant operational parameters are evaluated during the validation process to ensure that the device, backup systems, and alarms function as intended, the iNO set dose and measured dose remain within a prespecified range of each other at all times under all tested conditions, the fraction of inspired $\mathrm{O}_{2}\left(\mathrm{FiO}_{2}\right)$ is maintained within acceptable limits, $\mathrm{NO}_{2}$ generation is minimal, and any additional user instructions required for compatibility are identified. The validation process also ensures that there is no adverse effect on ventilator performance (eg, ventilation delivery performance and alarms).

Validation testing is conducted by trained respiratory therapists and device engineers, and the process involves a multistep evaluation to guarantee the compatibility of the mechanical ventilation system and iNO delivery system. During the first step in the validation process, mandatory and spontaneous ventilator modes are tested to affirm appropriate functionality of the iNO system across the full range of patients (ie, neonatal, pediatric, and adult) and ventilator modes for each ventilator. The iNO delivery device and mechanical ventilator are tested under clinically relevant normal and non-steady-state (ie, "worst case") conditions in each corresponding patient category (ie, neonate, pediatric, and adult) and with accessories (eg, humidifiers). In order to achieve validation, the following acceptance criteria must be met during pass/fail testing: 1) Oxygen dilution - all measured $\mathrm{O}_{2}$ values must be within the ventilator's specifications when compared with baseline $\mathrm{O}_{2}$ measured value before iNO is introduced into the gas delivery system. This is important because the addition of iNO dilutes the $\mathrm{O}_{2}$ concentration. 2) Effect on iNO on 
the ventilator device - no unexpected alarm conditions or anomalies can occur for either the ventilator or the iNO delivery system when the ventilator and iNO system are interfaced. Both devices must perform according to performance specifications for each. 3) Delivery accuracy all measured NO values must remain within accuracy specifications for the iNO delivery system. 4) $\mathrm{NO}_{2}$ generation $-\mathrm{NO}_{2}$ levels cannot exceed 1 ppm during the administration of $40 \mathrm{ppm}$ of iNO in $60 \% \mathrm{O}_{2}$ and cannot exceed 5 ppm during the administration of iNO at any dose setting in $100 \% \mathrm{O}_{2}$. If an issue emerges during the initial testing, secondary testing involves the manufacturer of the iNO delivery system (Mallinckrodt) working in conjunction with the ventilator manufacturer to resolve the issue. For example, in cases in which a ventilator fails to pass validation testing, the manufacturer may make updates to the iNO delivery system technology and/or collaborate with the ventilator manufacturer to rectify the issues observed during testing.

Once validation testing for each mechanical ventilator is complete ("pass" result is achieved for all parameters tested), results are reviewed by the iNO system manufacturer and submitted to the FDA for review and clearance before validation labeling is released to the public. Currently, iNO delivery systems have been ISO and MDSAP certified and validated for use with 63 different mechanical ventilators and gas delivery systems available in the United States and 44 different mechanical ventilators and gas delivery systems available outside the United States. The iNO delivery system complies with all FDA delivery device requirements and includes multiple alarms that monitor iNO delivery (including an abrupt discontinuation alarm), dosage (including an incorrect drug concentration alarm), and system functions; backup systems that include a backup drug cylinder and battery to provide uninterrupted iNO delivery; and constant monitoring of $\mathrm{NO}, \mathrm{NO}_{2}$, and $\mathrm{O}_{2}$ deliveries. A new iNO delivery system ( $\mathrm{DS}_{\mathrm{IR}}$ Plus MRI) has also recently received ISO 13485:2016 and MDSAP certifications for the administration of iNO in the magnetic resonance imaging suite. $^{46}$

\section{Summary and Conclusions}

Some clinicians use common medical devices in nonstandard ways and/or improvise workarounds to mitigate pragmatic challenges to the efficient delivery of patient care. ${ }^{9-14}$ Despite being well intended, unapproved modification of medical devices, such as the iNO delivery system, can increase the risk of life-threatening complications for patients. Underreporting and non-detection (eg, "near-misses") of medical errors are major barriers to patient safety. The true prevalence of device-related events caused by improvised devices is unknown because health care providers are not required (and may be reluctant) to report them to the FDA, especially if no harm has come to the patient. However, the person(s) modifying a given medical device assume the role of "manufacturer" and may bear legal and financial responsibility should any harm come to a patient as a result of the modified equipment. ${ }^{1,5-7}$ In some cases, professional malpractice insurance companies may exclude coverage for product design and manufacture or may have an "unlawful acts" exclusion that prevents them from providing coverage. Regulatory requirements set by safety organizations (eg, ISO 13485:2016, MDSAP) are evolving to mitigate these risks, and have put mechanisms in place to improve reporting of device-related incidents and to identify potential hazards.

The efficacy and safety of iNO has been established in several prospective clinical trials. However, safety parameters (eg, methemoglobin and $\mathrm{NO}_{2}$ concentrations) associated with the administration of iNO must be carefully monitored to avoid toxicity. $^{35,36,44}$ To minimize the risk of device-related malfunctions or errors, strict validation processes and procedures, such as those enforced by the iNO manufacturer, are required to ensure patient safety when interfaced medical devices are used in the critical care setting.

Medical devices and systems should always be used according to their intended purpose, and according to the regulatory and safety standards for which they have been approved. Clinicians are responsible for verifying that interfaced medical devices have been validated for the intended use according to the manufacturers' safety standards for each device. Unapproved modification or interfacing of medical devices can prevent the devices from working as intended across the full range of functionality and carries an unacceptable risk for device-related errors and adverse events for patients and professionals and a liability risk for clinicians.

\section{Abbreviations}

ECMO, extracorporeal membrane oxygenation; ECRI, Emergency Care Research Institute; FDA, US Food and Drug Administration; $\mathrm{FiO}_{2}$, fraction of inspired oxygen; ICU, intensive care unit; iNO, inhaled nitric oxide; ISO, International Organization for Standardization; IV, intravenous; MDSAP, Medical Device Single Audit Program; $\mathrm{MRI}$, magnetic resonance imaging; NO, nitric oxide; $\mathrm{NO}_{2}$, nitrogen dioxide; $\mathrm{O}_{2}$, oxygen. 


\section{Acknowledgments}

These data have been presented in part at the 2020 Respiratory Drug Delivery Meeting, April 26-30, 2020, as a poster presentation by DeWitt AL, Acker J, Larkin TA, Potenziano JL, and Schmidt JM, entitled "The Importance of Ensuring Compatibility When Interfacing Medical Devices in Neonatal Respiratory Care: Implications for Patient Safety." The poster was published in RDD Online, Respiratory Drug Delivery 2020, Volume 2, 2020: 307-310.

\section{Author Contributions}

All authors contributed to data analysis, drafting or revising the article, have agreed on the journal to which the article will be submitted, gave final approval of the version to be published, and agree to be accountable for all aspects of the work.

\section{Funding}

Medical writing and editorial support, which was conducted in accordance with Good Publication Practice (GPP3) and the International Committee of Medical Journal Editors (ICMJE) guidelines, was provided by Michael D. Morren, RPh, MBA, of Peloton Advantage, LLC, an OPEN Health company, funded by Mallinckrodt Pharmaceuticals.

\section{Disclosure}

Anthony L. DeWitt has received no compensation. Jaron Acker is an employee of Mallinckrodt Pharmaceuticals and may hold stock or stock options in that company; at the time the study was completed, he was part of Mallinckrodt's Medical Device Engineering Department. Thomas A. Larkin is an employee of Mallinckrodt Pharmaceuticals. Jim L. Potenziano is a former employee of Mallinckrodt Pharmaceuticals and holds stock in that company. Jeffrey M. Schmidt is a former employee of Mallinckrodt Pharmaceuticals. The authors report no other conflicts of interest in this work.

\section{References}

1. British Standards Institution. Medical Devices - Quality Management Systems - Requirements for Regulatory Purposes (ISO 13485:2016). London, United Kingdom: British Standards Institution; 2017.

2. Guidance document for premarket notification submissions for nitric oxide delivery apparatus, nitric oxide analyzer and nitrogen dioxide analyzer. Food and Drug Administration website; 2000. Available from: http://www.fda.gov/downloads/MedicalDevices/ DeviceRegulationandGuidance/GuidanceDocuments/ucm073767.pdf. Accessed November 25, 2019.
3. Medical Device Single Audit Program: Frequently Asked Questions; 2017. Available from: https://www.fda.gov/downloads/medicalde vices/internationalprograms/mdsappilot/ucm430563.pdf. Accessed: February 13, 2019.

4. Medical Device Single Audit Program (MDSAP); 2018. Available from: https://www.fda.gov/medicaldevices/internationalprograms/ mdsappilot/. Accessed February 13, 2019.

5. Laaperi v. Sears, Roebuck \& Co., Inc. 787 F.2d 726. 1986.

6. Werner v. Pittway Corp. 90 F.Supp.2d 1018. 2000.

7. Flock v. Scripto-Tokai Corp. 319 F.3d 231 5th Cir. 2003.

8. Classify Your Medical Device, 2020. Available from: https://www. fda.gov/medical-devices/overview-device-regulation/classify-yourmedical-device. Accessed: November 10, 2020.

9. Ruskin KJ, Tung A. If I had some duct tape, I could fix that. Anesth Analg. 2016;123(5):1072-1073. doi:10.1213/ANE.0000000000001550

10. El-Orbany M, Salem MR. Endotracheal tube cuff leaks: causes, consequences, and management. Anesth Analg. 2013;117 (2):428-434. doi:10.1213/ANE.0b013e318292ee21

11. Gogakos A, Barbetakis N, Lazaridis G, et al. Heimlich valve and pneumothorax. Ann Transl Med. 2015;3(4):54.

12. Diblasi RM. Nasal continuous positive airway pressure (CPAP) for the respiratory care of the newborn infant. Respir Care. 2009;54 (9):1209-1235.

13. van Wezel RAC, Vrancken ACT, Ernest M, Laurensse J. In hospital verification of non CE-marked respiratory protective devices to ensure safety of healthcare staff during the COVID-19 outbreak. J Hosp Infect. 2020;105(3):447-453. doi:10.1016/j.jhin.2020.05.023

14. Lowes T, Sharley P. Oxygen conservation during long-distance transport of ventilated patients: assessing the Modified Circle System. Air Med J. 2006;25(1):35-39. doi:10.1016/j.amj.2005.10.003

15. Fink JB. Opportunities and risks of using heliox in your clinical practice. Respir Care. 2006;51(6):651-660.

16. Managing risk during transition to new ISO tubing connector standards. Sentinel Event Alert. 2014. 53: 1-6.

17. Brown J. The life and death of the luer; 2012. Available from: https:// www.mddionline.com/life-and-death-luer. Accessed March 21, 2019.

18. Joint Commission on Accreditation of Healthcare Organizations. Tubing misconnections-a persistent and potentially deadly occurrence. Sentinel Event Alert. 2006. 36: 1-3.

19. Staebler S. Enteral feeding misconnections in the NICU: a continuing patient safety threat. Adv Neonatal Care. 2013;13(6):447-453. doi:10.1097/ANC.0000000000000032

20. Simmons D, Symes L, Guenter P, Graves K. Tubing misconnections: normalization of deviance. Nutr Clin Pract. 2011;26(3):286-293. doi: $10.1177 / 0884533611406134$

21. De Wet CJ, Affleck DG, Jacobsohn E, et al. Inhaled prostacyclin is safe, effective, and affordable in patients with pulmonary hypertension, right heart dysfunction, and refractory hypoxemia after cardiothoracic surgery. J Thorac Cardiovasc Surg. 2004;127 (4):1058-1067. doi:10.1016/j.jtcvs.2003.11.035

22. Bhatt AM, Stein EJ. Clinical complications with the delivery of inhaled epoprostenol in the operating room. Anesthesiology. 2017;127(2):383. doi:10.1097/ALN.0000000000001611

23. ECRI Institute. [Normal Priority]-H0315: ECRI Institute warns of equipment risks associated with use of inhaled epoprostenol [ECRI Exclusive Hazard Report]. 2016. Available from: www.ecri.org. Accessed November 25, 2019.

24. Giglio N, Lyvers J, Dave B. Error in inhaled nitric oxide setup results in "no delivery of iNO". APSF Newsletter. 2017;31(3):71.

25. McMullan DM, Bekker JM, Johengen MJ, et al. Inhaled nitric oxide-induced rebound pulmonary hypertension: role for endothelin-1. Am J Physiol Heart Circ Physiol. 2001;280(2):H777H785. doi:10.1152/ajpheart.2001.280.2.H777

26. Miller OI, Tang SF, Keech A, Celermajer DS. Rebound pulmonary hypertension on withdrawal from inhaled nitric oxide. Lancet. 1995;346(8966):51-52. doi:10.1016/S0140-6736(95)92681-X 
27. Atz AM, Adatia I, Wessel DL. Rebound pulmonary hypertension after inhalation of nitric oxide. Ann Thorac Surg. 1996;62 (6):1759-1764. doi:10.1016/S0003-4975(96)00542-5

28. Johnson KR, Hagadorn JI, Sink DW. Alarm Safety and Alarm Fatigue. Clin Perinatol. 2017;44(3):713-728. doi:10.1016/j. clp.2017.05.005

29. Cvach M, Stokes JE, Manzoor S, et al. Ventilator alarms in intensive care units: frequency, duration, priority and relationship to ventilator parameters [abstract]. Respir Care. 2018;63(suppl 10):2970168.

30. Belteki G, Morley CJ. Frequency, duration and cause of ventilator alarms on a neonatal intensive care unit. Arch Dis Child Fetal Neonatal Ed. 2018;103(4):F307-F311. doi:10.1136/archdischild2017-313493

31. Lawless ST. Crying wolf: false alarms in a pediatric intensive care unit. Crit Care Med. 1994;22(6):981-985. doi:10.1097/00003246199406000-00017

32. Edworthy J, Hellier E. Alarms and human behaviour: implications for medical alarms. Br J Anaesth. 2006;97(1):12-17. doi:10.1093/bja/ ael114

33. Siobal MS, Hess DR. Are inhaled vasodilators useful in acute lung injury and acute respiratory distress syndrome? Respir Care. 2010;55 (2):144-157.

34. INOmax [package insert]. Bedminster, NJ: INO Therapeutics; 2019.

35. Clark RH, Kueser TJ, Walker MW, et al. Low-dose nitric oxide therapy for persistent pulmonary hypertension of the newborn. Clinical Inhaled Nitric Oxide Research Group. $N$ Engl J Med. 2000;342(7):469-474. doi:10.1056/NEJM200002173420704

36. Davidson D, Barefield ES, Kattwinkel J, et al. Inhaled nitric oxide for the early treatment of persistent pulmonary hypertension of the term newborn: a randomized, double-masked, placebo-controlled, dose-response, multicenter study. The I-NO/PPHN Study Group. Pediatrics. 1998;101(3 Pt 1):325-334. doi:10.1542/peds.101.3.325

37. Roberts JD Jr, Fineman JR, Morin FC III, et al. Inhaled nitric oxide and persistent pulmonary hypertension of the newborn. The Inhaled Nitric Oxide Study Group. N Engl J Med. 1997;336(9):605-610. doi:10.1056/NEJM199702273360902
38. INOmax $\mathrm{DS}_{\mathrm{IR}}$ Plus Operation Manual. Madison, WI: Mallinckrodt Manufacturing. 2014.

39. Cosa N, CostaE Jr. Inhaled pulmonary vasodilators for persistent pulmonary hypertension of the newborn: safety issues relating to drug administration and delivery devices. Med Devices. 2016;9:45-51. doi:10.2147/MDER.S99601

40. Lavoie A, Hall JB, Olson DM, Wylam ME. Life-threatening effects of discontinuing inhaled nitric oxide in severe respiratory failure. Am J Respir Crit Care Med. 1996;153(6 Pt 1):1985-1987. doi:10.1164/ ajrccm.153.6.8665066

41. Cueto E, Lopez-Herce J, Sanchez A, Carrillo A. Life-threatening effects of discontinuing inhaled nitric oxide in children. Acta Paediatr. 1997;86(12):1337-1339. doi:10.1111/j.1651-2227.1997. tb14909.x

42. Wedgwood S, McMullan DM, Bekker JM, Fineman JR, Black SM. Role for endothelin-1-induced superoxide and peroxynitrite production in rebound pulmonary hypertension associated with inhaled nitric oxide therapy. Circ Res. 2001;89(4):357-364. doi:10.1161/ hh1601.094983

43. Peliowski A. Inhaled nitric oxide use in newborns. Paediatr Child Health. 2012;17(2):95-100. doi:10.1093/pch/17.2.95

44. The Neonatal Inhaled Nitric Oxide Study Group. Inhaled nitric oxide in full-term and nearly full-term infants with hypoxic respiratory failure. The Neonatal Inhaled Nitric Oxide Study Group [published correction appears in N Engl J Med. 1997;337:434]. N Engl J Med. 1997;336(9):597-604. doi:10.1056/NEJM199702273360901

45. INOmax [product monograph]. Dundas, ON, Canada: C.R.I. 2017.

46. Mallinckrodt earns international standard ISO 13485:2016 and medical device single audit program (MDSAP) certifications for INOmax DSIR Plus nitric oxide delivery systems [press release]. 2018. Available from: http:/www.mallinckrodt.com/about/news-and-media/. Accessed March 21, 2019.
Medical Devices: Evidence and Research

\section{Publish your work in this journal}

Medical Devices: Evidence and Research is an international, peerreviewed, open access journal that focuses on the evidence, technology, research, and expert opinion supporting the use and application of medical devices in the diagnosis, monitoring, treatment and management of clinical conditions and physiological processes. The identification of novel devices and optimal use of existing devices

\section{Dovepress}

which will lead to improved clinical outcomes and more effective patient management and safety is a key feature of the journal. The manuscript management system is completely online and includes a very quick and fair peer-review system. Visit http:// www.dovepress.com/testimonials.php to read real quotes from published authors. 